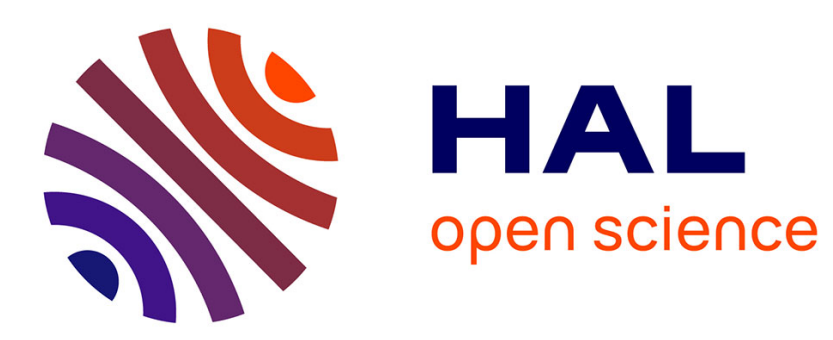

\title{
Market Size and Vertical Equilibrium in the Context of Successive Cournot Oligopolies
}

\author{
Ivan Dufeu
}

\section{To cite this version:}

Ivan Dufeu. Market Size and Vertical Equilibrium in the Context of Successive Cournot Oligopolies. B.E. Journal in Theoretical Economics, Topics in Theoretical Economics, 2004, 4 (1), 10.2202/1534598X.1122 . hal-02816481

\section{HAL Id: hal-02816481 \\ https://univ-angers.hal.science/hal-02816481}

Submitted on 25 Jun 2021

HAL is a multi-disciplinary open access archive for the deposit and dissemination of scientific research documents, whether they are published or not. The documents may come from teaching and research institutions in France or abroad, or from public or private research centers.
L'archive ouverte pluridisciplinaire HAL, est destinée au dépôt et à la diffusion de documents scientifiques de niveau recherche, publiés ou non, émanant des établissements d'enseignement et de recherche français ou étrangers, des laboratoires publics ou privés. 


\title{
Topics in Theoretical Economics
}

Volume 4, Issue 1

2004

Article 2

\section{Market Size and Vertical Equilibrium in the Context of Successive Cournot Oligopolies}

\author{
Ivan Dufeu*
}

*Normandy Business School, France, ivan.dufeu@univ-rennes1.fr

Copyright (C)2004 by the authors. All rights reserved. No part of this publication may be reproduced, stored in a retrieval system, or transmitted, in any form or by any means, electronic, mechanical, photocopying, recording, or otherwise, without the prior written permission of the publisher, bepress. Topics in Theoretical Economics is one of The B.E. Journals in Theoretical Economics, produced by The Berkeley Electronic Press (bepress). http://www.bepress.com/bejte. 


\title{
Market Size and Vertical Equilibrium in the Context of Successive Cournot Oligopolies*
}

\author{
Ivan Dufeu
}

\begin{abstract}
This paper illustrates the effect of market size on the decision of whether or not firms should vertically integrate or disintegrate. We use a model of two successive stages of production with Cournot competition in each stage. In this model, firms choose to specialize (either upstream or downstream) or to integrate the two stages, before making their production decisions. The decision of whether or not to integrate or specialize depends on the trade-off between "escaping from" the double marginalization problem or the gain from specializing in the production stage in which the firm is more efficient. We show (using simulations) that more firms choose to be vertically integrated as the valuation of the final product or the number of consumers increases, unless the number of firms increases proportionately.
\end{abstract}

KEYWORDS: Vertical integration, vertical equilibrium, industry growth, successive Cournot oligopoly, double marginalization effect.

*Ivan Dufeu Normandy Business School 30 rue de Richelieu 76087 Le Havre, France Member of the CREM (UMR CNRS 6211) tel : +33232927082 


\section{INTRODUCTION}

Existing economic theories have provided little analysis of vertical disintegration while focusing on integration. This is surprising as Adam Smith indirectly mentioned the issue in his analysis of the division of labor. Actually, the few contributions to vertical disintegration are built on Adam Smith's proposition that the division of labor is limited by the extent of the market (Young (1928), Pigou (1932), Stigler (1951)). In applying Smith's theorem, Stigler (1951) argued that vertical disintegration is the typical evolution of a growing industry, whereas a declining industry must be characterized by vertical integration. Stigler offers a testable proposition, regarding industry growth and vertical integration. His vertical separation argument is that, as the market demand increases, it is more economic for the firms in the industry to purchase some of their inputs from specialized firms, who can reap economies of scale from large scale operation. Conversely, as the industry demand falls, firms will produce in-house inputs that were formerly outsourced. In other words, vertical disintegration is the typical evolution of an industry in growth, while vertical integration that of an industry in decline.

The following empirical research is investigating the validity of Stigler's proposition. Tucker and Wilder (1977) examined 54 American manufacturing firms, and Levy (1984) explored census data for 38 industries from 1963, 1967 and 1972 : they found some support to Stigler's conjecture. Subsequently, Wright and Thompson (1986) tested Stigler's hypothesis with data on 407 investment withdrawals in the UK between 1977 and 1979. They showed that vertical disintegration is positively correlated with industry growth. By contrast, Stuckey (1983) found opposite results from the study of the aluminum industry. Thus, the results are inconclusive.

In this paper, we construct a model of vertical equilibrium allowing theoretical examination of Stigler's hypothesis, within a framework of Cournot competition. We examine equilibria where integrated and specialized firms coexist, and we confront the vertical equilibrium to modifications of the market size. In this context of successive Cournot oligopolies, Salinger (1988) shows, in a two stages model with fixed proportions, that vertical integration can result from the double mark-up effect. But he simply imposes the coexistence of integrated and specialized firms, without studying the integration game. Gaudet and Van Long (1996) do examine the vertical equilibrium in a model of successive Cournot oligopolies and show that complete integration emerges in most circumstances, with only one specific configuration leading to the realistic coexistence of integrated and specialized firms. However, they do not introduce ${ }^{1}$

\footnotetext{
${ }^{1}$ Because their main purpose is to study foreclosure strategy at equilibrium and not really the vertical integration degree.
} 
the motivations of disintegration : we believe that explains why vertical integration is dominant in these models. So, we do assume that there exist economies from specialization of the firms.

Actually, as pointed out by White (1978), the dynamics of vertical integration-disintegration cannot derive exclusively from the existence of economies of scale, contrary to what was suggested by Stigler (1951). If there are economies of scale for the production of an input, these cost savings could also be realized internally by the integrated firm. So, vertical disintegration comes from economies from performing a limited set of tasks, as opposed to economies from repeatedly performing any one activity. Perry (1984) do introduce economies from specialization, in a two stage model of vertical equilibrium with fixed proportions. These economies come from final demand fluctuations which tend to increase profits of specialized firms relatively to integrated ones. He characterized a vertical equilibirum where upstream, downstream and integrated firms coexist. However, by explaining vertical integration from economies of synchronization, this model doesn't allow to examine the relationship between vertical equilibrium and industry growth.

Perry and Groff (1988) propose a vertical equilibrium model where vertical disintegration comes from differences in the firm's competencies. In their model, each firm is endowed with a separate cost function for each stage, and the firms which are more efficient in upstream production are less efficient for the downstream production. Perry and Groff assume that the average cost curves are increasing for downstream production, decreasing upstream and U-shaped for the integrated firms. Consecutively, they assume imperfect competition in the intermediate market and perfect competition in the final market, which explains the benefits of vertical integration. For a given linear final demand, a vertical equilibrium can be defined, for which the firms make a choice between upstream or downstream specialization, and confronted to shifts in the demand size. They conclude that Stigler's hypothesis was verified only in specific circumstances.

In the vein of Perry and Groff's paper, Elberfeld (2002) constructs a model of two vertically related Cournot oligopolies (with economies of scale at each stage) and analyzes the relationship between market size and vertical integration. In his model, integrated and specialized firms can coexist and compete. The specialization or the integration choice is not explained by differences in firm's competencies but by differences in the cost functions of integrated compared to specialized firms. The disadvantage of unintegrated downstream firms is that they bear higher variable costs associated with imperfect competition upstream. On the other hand, producing the intermediate good entails fixed costs which can partly be saved by outsourcing. In this context, he notably shows that the degree of vertical integration decreases with market size, when entry into the market is free, which confirms Stigler's hypothesis. Eleberfeld's contribution has the real 
advantage that the number of firms is endogenous. However, this advantage relies on some strong assumptions : Elberfeld ignores the double marginalization problem while assuming that downstream firms have no oligopsony power (they are price takers). Moreover, upstream firms do not have the ability to integrate downstream, which they would sometimes do if the downstream oligopsony power was considered. Finally, unintegrated production of the intermediate good is supposed to entail fixed costs and no variable cost : so, the upstream stage is not really considered as a market, but more as a "technical investment". With this framework, there are no real economies of specialization, as the total cost of an integrated firm is lower than the sum of upstream and downstream costs (in the described equilibria). The main explanation for the existence of specialized downstream firms comes from their lower fixed costs compared to integrated firms. His results are very sensitive to the ad-hoc assumption on fixed costs : as the number of firms grows, their profitability losses become comparatively lower.

Our model is closely related to Perry and Groff (1988) and to some extent to Elberfeld (2002). We follow Perry and Groff for the main hypothesis of "a continuum of agents with different skills", but new assumptions are formulated relating to technologies and competition frameworks. Yet, it is not clear why a given cost curve or a given type of competition should correspond to a given stage. Indeed, we focus here on two successive stages, which can be located anywhere along a production process potentially implying many stages. We can only assume that the various implied technologies require different skills. So, we consider here that the form of the upstream and downstream costs curves and the competition frameworks do not differ. Moreover, it seems to be more logical to assume imperfect competition at each stage ${ }^{2}$ (like in Elberfeld (2002)) because of the limited number of firms considered in their model (usually less than 7 firms at each stage in the examined equilibria) and in ours. Actually, the number of firms in the industry must not be so large that competition in the downstream production drives the final price below the minimum average cost of integrated firms. Finally, in Perry and Groff's model, there is a paradox between excluding partial integration and assuming no fixed cost (and growing marginal costs) in downstream production. Actually, in this context, upstream firms are strongly incited to produce small quantities of the final good with their own intermediate production, and to sell the rest to final specialists. Furthermore, the integrated firms should not use all their intermediate production for their final production, because of the diseconomies of scale. Nevertheless, they rule out the possibility that a firm could be a net supplier or demander of the intermediate good. By assuming that there exist fixed costs and constant marginal costs for each technology, as we do here, partial integration becomes much less probable.

\footnotetext{
${ }^{2}$ We assume Cournot competition at each stage. Had we assumed Bertrand competition, the results would have been qualitatively the same, because of the differences in firm's competencies.
} 
The model considers the presence of a number $n$ of firms playing a two stages game. In the first stage, firms decide whether to specialise in either the upstream or the downstream production, or to be vertically integrated. In the second stage, upstream and downstream production decisions are taken by the firms that compete in quantities at both stages of production. The rest of the paper is organized as follows. Section 2 describes the model. Assuming a linear final demand, section 4 characterizes the vertical equilibrium. This vertical equilibrium depends on horizontal oligopoly equilibrium at each stage of the process (section 3). Section 5 tests Stigler's hypothesis through a simulation while analyzing the impact of a modification in the size of demand on the proportion of vertically integrated firms. Section 6 concludes.

\section{THE MODEL}

The model comprises two successive stages of production (an intermediate and a final one) and three types of producers : integrated, downstream and upstream firms. An integrated firm produces both the final good and the intermediate good, with the latter used as an input in the production of the final good. An upstream firm produces only the intermediate good, while a downstream firm produces the final good and buys the intermediate good on the open market. The firms produce with fixed-coefficient technology: one unit of the intermediate good is required to produce one unit of the final good. Lastly, each firm can choose to operate in one or both of the two stages.

The firms differ in their efficiency in producing intermediate and final goods. We assume this not only because it is usually observed in reality (see Gaudet and al. (1996) for the world oil industry), but also because skills and specialization choices are closely correlated and because these differences of skills explain diseconomies of vertical scope. Following Perry and Groff (1988), we assume that firms that are more efficient in downstream production are less efficient in upstream production, and vice versa. Efficiency is defined as lower total costs for producing all outputs levels. We pose, as they do, a cost parameter $\theta$ specific for every firm, where $0 \leq \theta \leq 1$, such that firms with a $\theta$ near one have a relative advantage in upstream technology, whereas firms with a small $\vartheta$ have a relative advantage in downstream technology. Industry is composed of an exogenous number of firms, $n$. If $n$ is not too large, every stage of the production process is characterized by an oligopoly : we assume Cournot competition. It is not possible in our model to permit free entry or exit of firms, nor horizontal integration, because only the most efficient firms would exist in equilibrium. We consider that the $n$ firms, each characterized by a specific $\theta$, are distributed on $[0 ; 1]$ so that the distance between two neighboring firms is constant for a given $n$. 
Entry or exit can only be addressed by increasing or decreasing $n$. All the firms have the information on the distribution of $\theta$.

Every firm faces constant marginal costs and fixed costs (decreasing average costs $)^{3}$. A priori, we can assume that $\theta$ affects either marginal costs or fixed cost, without modifying the qualitative results of our story. Perry and Groff (1988) assume for example that efficiency differences in upstream production are reflected in different fixed costs, and those in downstream production are modeled by differences in marginal costs : but assuming differences in marginal costs raises calculation problems due to discontinuity (this problem is not mentioned by Perry and Groff). Actually, when the downstream firms have different marginal costs, their output choices systematically differ, depending on their $\theta$. We therefore have to adopt a continuity hypothesis in order to calculate the aggregate output of downstream producers by integrating on $\theta$. With this hypothesis, we cannot give the closed form solution of the model but only an approximation of the exact vertical equilibrium. The lower the number of firms $n$, the worse the approximation will be. This approximation is a weakness Perry and Groff's model : they consider a limited number of firms, whereas continuity hypothesis implies that each firm's decision has an insignificant impact at industry level. So, we choose to assume that all firms have the same marginal cost for each stage, the differences in efficiency being reflected in fixed cost.

Let $f$ be the fixed cost of the least efficient firm for downstream production $(\theta=1)$. We can then pose that $\theta f$ is the downstream fixed cost of every other firm $\theta$. With such a cost structure, the most efficient agent has no fixed cost ( $\theta=0)$ for downstream production. If $y_{\theta}$ is the output of final good by firm $\theta$ and $c$ the marginal cost for downstream production, its downstream total cost ${ }^{4}$ is :

$$
C_{\theta}^{d}\left(y_{\theta}\right)=\theta \cdot f+c \cdot y_{\theta}
$$

In a similar way, let $\varphi$ be the fixed cost of the most efficient firm $\theta=1$ for upstream production. We can then define the upstream fixed cost of all other firms as $\varphi / \theta$. If $y_{\theta}$ is the output of intermediate good by firm $\theta$, and $\chi$ the marginal cost for upstream production, the total cost is :

$$
C_{\theta}^{u}\left(y_{\theta}\right)=\varphi / \theta+\chi y_{\theta}
$$

\footnotetext{
${ }^{3}$ This assumption is not critical to our model and is compatible with Cournot competition.

${ }^{4}$ The variable cost of buying intermediate goods will be introduced into the profit function.
} 
We integrate neither economies nor diseconomies of vertical integration : both exist, but they are likely to compensate each other in practice. So we consider the total cost function of the integrated firms is the simple algebraic sum of the upstream and downstream costs. Thus, if $x_{\theta}$ is the output of the final goods of an integrated firm $\theta$, its total cost is :

$$
C_{\theta}^{i}\left(x_{\theta}\right)=\theta \cdot f+\varphi / \theta+(\chi+c) \cdot x_{\theta}
$$

On the demand side, we assume that the final consumers $i$, with exogenous total number $I$, all behave the same way and have a linear individual demand function :

$$
q_{i}=\alpha-\beta p
$$

With $y$ the aggregate final output of specialized firms and $x$ that of integrated firms, the aggregate inverse demand function is :

$$
p(x, y)=\alpha / \beta-\left(\frac{x+y}{\beta I}\right)
$$

or, with $a=\alpha / \beta$ and $b=1 /(\beta . I)$,

$$
p(x, y)=a-b(x+y)
$$

Growth in demand must mainly be captured by a rise in the number $I$ of consumers, associated with a fall of $b$. A rise of $a$ (or $\alpha$ ) corresponds with an increase in the value granted by each consumer to the final $\operatorname{good}^{5}$. It can therefore be regarded as a form of growth of the market size. Modifying $\beta$ raises no interesting question because it impacts simultaneously $a$ and $b$.

To formalize Stigler's idea, we work on a vertical equilibrium which is defined by $(\underline{\theta}, \bar{\theta})$, with $0<\underline{\theta}<\bar{\theta}<1$. The firms with an index $\theta$ such as $0 \leq \theta<\underline{\theta}$ produce only the intermediate goods, the firms with an index $\theta$ such as $\underline{\theta} \leq \theta<\bar{\theta}$ are integrated, and the others are firms specialized in the downstream production. Theoretically this equilibrium can be defined if the oligopoly markups are significant. This will result of the firm's production choice (based on their relative profits) which depends on their index of efficiency. Because of the previous assumptions, the profits of the downstream firms must decrease when $\theta$ increases and the profits of the upstream firms must increase. A firm highly qualified for the downstream (upstream) production will maximize its profit while specializing

\footnotetext{
${ }^{5}$ This leads to a decrease in the price elasticity of consumption which is independent of $I$.
} 
according to its comparative advantage although it undergoes the upstream (downstream) oligopoly mark-up. If a firm is fairly effective with both technologies ( $\theta$ around 0.5), profit maximization can lead to an integration of the two stages, giving up the benefit of specialization (weak in it's situation) so as to avoid the double marginalization. To determine this vertical equilibrium, the horizontal equilibrium is characterized at each stage in section 3.

\section{HoRIzonTAl EQUILIBRIUM}

The Cournot horizontal equilibrium determines the profit-maximizing outputs for integrated, downstream and upstream firms. Let the number of firms and the demand size be such as : i) the final price $p^{*}$ exceeds the marginal cost (which is also the variable average cost) of integrated firm $\left(p^{*}>(c+\chi)\right)$; ii) the intermediate equilibrium price exceeds the marginal cost of upstream firms $\left(r^{*}>\chi\right)$; iii) the final price $p^{*}$ exceeds the marginal cost of downstream firms $\left(p^{*}>r^{*}+c\right)$. Otherwise, some firms would not be profitable.

\subsection{Optimum for integrated firms}

The integrated firms must choose between two possibilities:

- Withdraw from the intermediate market and to use all their intermediate production for their final production.

- Take part in the intermediate market by selling intermediate goods to the downstream firms, and/or buying these goods from the upstream firms.

In our model, this choice is dependant upon many circumstances. For an integrated firm, selling intermediate goods to the downstream firms can increase the scale of its upstream production, and thus reduce the upstream average cost (because of the fixed costs). But this introduces more competition upstream and therefore lowers the intermediate price offered to the downstream specialists who are direct competitors of the integrated firms. Buying intermediate goods from upstream specialists presents conversely the advantage of increasing the price charged by the upstream specialists and thus of degrading the competitiveness of the downstream firms compared to integrated firms. However, that increases the supplying price of the integrated firms (since it can produce at a marginal cost lower than the upstream market price), thus reduce the level of their in-house upstream production which increases the average upstream cost.

Gaudet and Long Van (1995) show that no general answer can be given concerning these problems, even if one supposes very simple cost functions (constant marginal cost and no fixed costs) and absence of competence

differentiation. But according to Salinger (1988), it is especially in the presence of 
increasing average cost that the integrated firms can have an interest sometimes to take part in the intermediate market.

So let us assume that the integrated firms use all and only their intermediate output for their final production. If $x_{\theta}$ is the production of the integrated firm $\theta$ and if $x_{0}$ is the total production of the other integrated firms (so we have $\left.x_{\theta}+x_{0}=x\right)$, then the profit function of the firm $\theta$ can be expressed as :

$$
\pi_{\theta}^{i}=p\left(x_{\theta}+x_{0}, y\right) \cdot x_{\theta}-(c+\chi) \cdot x_{\theta}-\theta f-\varphi
$$

The output firm $\theta$ sets is :

$$
x_{\theta}=(a-c-\chi) / b-x-y
$$

Firms have the information on the distribution of firms on $[0,1]$. So they know that the number of integrated firms is simply $n \cdot(\bar{\theta}-\underline{\theta})$, and that firms differ only in their fixed costs. This means that they know that each integrated firm $\theta$ will produce the same output $x_{\theta}=\frac{x}{n \cdot(\bar{\theta}-\underline{\theta})}$. So it comes :

$$
x\left[1+\left(\frac{1}{n \cdot(\bar{\theta}-\underline{\theta})}\right)\right]+y=\frac{(a-c-\chi)}{b}
$$

This gives the output supplied by integrated firms given the output of specialized firms and the vertical equilibrium.

\subsection{Optimum for downstream firms}

If $y_{\theta}^{d}$ is the production of the downstream firm $\theta$ and if $y_{0}^{d}$ is the total production of the other downstream firms, then the downstream firm $\theta$ 's profit is :

$$
\pi_{\theta}^{d}\left(y_{\theta}^{d}, y_{0}^{d}, x\right)=p\left(y_{\theta}^{d}+y_{0}^{d}, x\right) \cdot y_{\theta}^{d}-(r+c) \cdot y_{\theta}^{d}-\theta . f
$$

Firms know that the number of downstream firms is simply $n \cdot \underline{\theta}$ and that each downstream firm $\theta$ will produce the same output $y_{\theta}^{d}=\frac{y}{n \cdot \underline{\theta}}$. Considering the first order condition from (7), and substituting for $p(x, y)$, equation (8) defines the inverse demand function of the intermediate good for each upstream firm :

$$
r(y, x)=a-c-b \cdot x-b\left(1+\frac{1}{n \underline{\theta}}\right) y
$$




\subsection{Optimum for upstream firms}

If $y_{\theta}^{u}$ is the production of the upstream firm $\theta$ and if $y_{0}^{u}$ is the total production of the other upstream firms, then the profit function of the upstream firm $\theta$ is :

$$
\pi_{\theta}^{u}\left(y_{\theta}^{u}+y_{0}^{u}, x\right)=r\left(y_{\theta}^{u}+y_{0}^{u}, x\right) \cdot y_{\theta}^{u}-\chi y_{\theta}^{u}-\varphi / \theta
$$

Each upstream firm produces $y /(1-\bar{\theta})$. Substituting for $r(x, y)$ from (7) and maximizing, we have :

$$
b\left[\frac{1}{n(1-\bar{\theta})}+1\right]\left(\frac{1}{n \underline{\theta}}+1\right) y+b x=(a-c-\chi)
$$

\subsection{Horizontal complete equilibrium}

Conditions (6) and (10), simultaneously define the equilibrium outputs $x *$ and $y^{*}$ given the vertical boundaries $(\underline{\theta}, \bar{\theta})$. Let's normalize to unity the cost parameters $\mathrm{c}$ and $\chi$, which raise no interesting questions and don't impact our conclusions.

$$
\begin{aligned}
x^{*} & =\frac{n(a-2)(1+n(1-\bar{\theta}+\underline{\theta}))(\bar{\theta}-\underline{\theta})}{b\left[n^{2}\left(\bar{\theta} \underline{\theta}-\underline{\theta}^{2}+\bar{\theta}(1-\bar{\theta})\right)+1+n\right]} \\
y^{*}= & \frac{n^{2}(a-2) \underline{\theta}(1-\bar{\theta})}{b\left[n^{2}\left(\bar{\theta} \underline{\theta}-\underline{\theta}^{2}+\bar{\theta}(1-\bar{\theta})\right)+1+n\right]}
\end{aligned}
$$

Condition (8) gives the equilibrium intermediate price $\mathrm{r}^{*}(\underline{\theta}, \bar{\theta})$ and condition (4) the equilibrium final price $\mathrm{p}^{*}(\underline{\theta}, \bar{\theta})$. We have here the complete characterization of horizontal equilibrium which is necessary to describe vertical equilibrium.

\section{VERTICAL EQUILIBRIUM}

Vertical equilibrium defines the stage of production in which agents will choose to operate. It is assumed that the firm with index $\underline{\theta}$ is indifferent between operating as a downstream firm or being integrated, both of which being more profitable than producing only the intermediate good. Similarly, the firm with index $\bar{\theta}$ is indifferent between being specialized in the upstream production or being integrated, both being more profitable than operating as a downstream firm. Determining these boundaries will thus tell us which firms will choose to 
specialize downstream $(\theta<\underline{\theta})$, which firms will maximize their profit while being integrated $(\underline{\theta}<\theta<\bar{\theta})$ and which firms will specialize upstream $(\theta>\bar{\theta})$.

Given the horizontal equilibrium, we examine the firms profits at each index for each stage to characterize this vertical equilibrium. These profit functions are :

$$
\begin{aligned}
& \pi^{d}(\theta ; \underline{\theta}, \bar{\theta})=\left(p^{*}-r^{*}-1\right) \cdot \frac{y^{*}}{n \cdot \underline{\theta}}-\theta \cdot f \\
& \pi^{i}(\theta ; \underline{\theta}, \bar{\theta})=\frac{(p-2)^{2}}{b}-\theta f-\frac{\varphi}{\theta} \\
& \pi^{u}(\theta ; \underline{\theta}, \bar{\theta})=\frac{(r-1)^{2}}{b(1 / n \underline{\theta}+1)}-\frac{\varphi}{\theta}
\end{aligned}
$$

The boundaries $\underline{\theta}^{*}$ and $\bar{\theta} *$ are defined by conditions (16) and $(17)^{6}$.

$$
\begin{aligned}
& \pi^{u}\left(\underline{\theta}^{*} ; \underline{\theta}^{*}, \bar{\theta}^{*}\right)=\pi^{i}\left(\underline{\theta}^{*} ; \underline{\theta}^{*}, \bar{\theta}^{*}\right) \\
& \pi^{i}\left(\bar{\theta}^{*} ; \underline{\theta}^{*}, \bar{\theta}^{*}\right)=\pi^{d}\left(\bar{\theta}^{*} ; \underline{\theta}^{*}, \bar{\theta}^{*}\right)
\end{aligned}
$$

A full vertical equilibrium exists if $0<\underline{\theta}^{*}<\bar{\theta} *<1$. There can be no integrated firm $\left(\underline{\theta}^{*}=\bar{\theta} *\right)$ or only integrated firms in equilibrium $\left(\underline{\theta}^{*}=0\right.$ et $\left.\bar{\theta} *=1\right)$ but these cases are not relevant to our problem, which is to test Stigler's idea.

Finally, to define the vertical equilibrium, we need to solve the simultaneous equations system (4), (8), (11), (12), (16) and (17). Analytical comparative statics on the vertical equilibrium are intractable, so we do numerical comparative statics over a wide range of values for market size parameters.

\section{VERTICAL EQUILIBRIA AND INDUSTRY GROWTH}

The purpose of this model of vertical equilibrium is to test the Stigler's hypothesis according to which growing industries would be characterized by vertical disintegration, and, conversely, declining industries by vertical integration. We will thus evaluate the impact on the vertical equilibrium of modifications in the value of the model's parameters that are correlated with market size. Industry growth can of course be captured by changing the demand parameters a and $\mathrm{b}$. However, on the supply size, it is important to evaluate the impact of an increase in the total number of firms $n$ that can come with demand growth.

\footnotetext{
${ }^{6}$ We can well observe a rise of $\pi^{\mathrm{u}}$ and a fall of $\pi^{\mathrm{d}}$ when $\theta$ increase ; the simulation shows us that $\pi^{\mathrm{i}}$ is higher than $\pi^{\mathrm{u}}$ and $\pi^{\mathrm{d}}$ for firms with $\theta$ near 0.5 for a wide range of the parameters.
} 
We focus only upon the cases where there is a full vertical equilibrium, i.e where three types of firms exist. We consider consistent (relative at the marginal costs and at the demand size) values for fixed costs ${ }^{7}$ : we posit $\mathrm{f}=40$ and $\varphi=10$.

\subsection{Increase in the number of firms}

The increase in the number of firms in the industry is accompanied by a fall of the relative and absolute number of integrated firms. The integrated stage contracts from above and below (see table 1).

A rise in the total number of firms generates an additional competition on each stage that lowers oligopoly markups and increases supplied quantities ${ }^{8}$ for the three types of firms (with Cournot conjecture). The subsequent increase in intermediate demand works in the opposite direction for upstream markups but, in our model, the former effect is stronger than the latter. We checked by simulation that the final and intermediate prices drop and that total output increases with a growing number of firms. The integrated firms close to old equilibrium boundary $\underline{\theta}^{*}$ specialize downstream (rise in $\underline{\theta}$ ) to benefit from the fall in intermediate price. Those close to old equilibrium boundary $\bar{\theta}^{*}$ give up downstream technology (decrease in $\bar{\theta}$ ) because of the decreasing downstream markup and of the increased intermediate demand. Integrated stage disappears if total number of firms becomes large enough.

Table I : Increasing the number of firms (with $\beta=0.02, \alpha=2, I=25$ )

\begin{tabular}{|c|c|c|c|c|c|c|}
\hline $\mathrm{n}$ & 10 & 15 & 20 & 25 & 30 & 35 \\
\hline$\underline{\theta}$ & 0.15 & 0.23 & 0.29 & 0.32 & 0.35 & 0.37 \\
$\bar{\theta}$ & 0.93 & 0.77 & 0.66 & 0.59 & 0.53 & 0.49 \\
\hline Integrated Firms (share) & $78 \%$ & $54 \%$ & $37 \%$ & $27 \%$ & $18 \%$ & $12 \%$ \\
Downstream F (share) & $15 \%$ & $23 \%$ & $29 \%$ & $32 \%$ & $35 \%$ & $37 \%$ \\
Upstream F (share) & $7 \%$ & $23 \%$ & $34 \%$ & $41 \%$ & $47 \%$ & $51 \%$ \\
\hline
\end{tabular}

\footnotetext{
${ }^{7} \mathrm{~A}$ rise in the fixed costs for downstream technology leads to a vertical equilibrium for which the number of downstream firms decreases but especially for which the number of integrated firms very strongly falls ; this can be explained by the fact that the integrated firms have a higher fixed cost for downstream technology (because their index $\theta$ is higher). A rise in $\varphi$ affect identically integrated firms and upstream firms (thus $\bar{\theta}$ does not change) but does not affect downstream firms, which increases the incentive to specialize downstream (rise of $\underline{\theta}$ ).

${ }^{8}$ The integrated firms are indeed in competition with the downstream firms, therefore even their number falls, the number of their competitors increases (cf table 1).
} 
So with the additional competition on each stage when the number of firms rise, it becomes less advantageous to be vertically integrated to escape double marginalization. The firms will have a growing interest to specialize according to "their comparative advantage" in terms of skills. This is an interesting preliminary result, but an increase in the number of firms cannot be regarded as a reliable indicator of the market size. It is the rise in the number of consumers and/or in the value which they grant to the product, which leads to industry growth.

\subsection{Growth in the number of consumers}

By fixing the demand parameters $\beta$ and $\alpha$ and the number $N$ of firms, we examine industry growth which occurs by increasing number of consumers $I$ (Table 2).With the rise of the number of consumers, the slopes of the direct and derived inverse demand curves decrease, the produced quantities $x$ and $y$ increase in the same proportion, but the prices $p$ and $r$ are not modified firstly (because demand is linear). Thus, the rise in the proportion of integrated firms does not come initially from an increase in the upstream oligopoly margin. If we look, on the other hand, at the profit functions of the three types of firms, we observe that a increase in the number of consumers induces a stronger rise of profit for integrated firms than for upstream and downstream firms. This results of the higher fixed costs in the integrated firms than in specialized firms. Actually, if the production scale increases and when marginal costs are constant, the profit increase is stronger for firms with higher fixed costs.

Table II : Growth in the number of consumers (with $\beta=0.02, \alpha=2, n=15$ )

\begin{tabular}{|c|c|c|c|c|c|c|}
\hline I & 5 & 10 & 15 & 25 & 40 & 60 \\
\hline$\underline{\theta}$ & 0.30 & 0.26 & 0.24 & 0.21 & 0.18 & 0.15 \\
\hline $\bar{\theta}$ & 0.49 & 0.61 & 0.70 & 0.81 & 0.91 & 0.97 \\
\hline Integrated firms (share) & $18 \%$ & $34 \%$ & $46 \%$ & $61 \%$ & $72 \%$ & $82 \%$ \\
\hline Downstream F (share) & $30 \%$ & $27 \%$ & $24 \%$ & $21 \%$ & $19 \%$ & $15 \%$ \\
\hline Upstream F (share) & $52 \%$ & $39 \%$ & $30 \%$ & $18 \%$ & $9 \%$ & $3 \%$ \\
\hline
\end{tabular}

If it is this scale effect which explains the initial increase in the proportion of integrated firms, this tendency induces modifications of the competing situation for each stage that will impact on final equilibrium. Indeed, the subsequent fall in the number of upstream firms is accompanied by a rise in the oligopoly markup and thus induces downstream firms near to the old equilibrium boundary $\underline{\theta}^{*}$ to integrate upstream technology. But on the other hand, the decrease in the number 
of independent downstream firms (accentuated by the former effect) tends to lower their intermediate demand. This moderates the increase in the oligopoly price. We verified by simulation, that the first effect is stronger than the second.

Proposition 1 : A growing number of consumers leads to an increasing proportion of firms choosing to be vertically integrated.

This result comes however partly from the scale effect. To cancel this effect and to focus on the strategic behaviors, we next consider that the number of consumers and the number of firms increase proportionately.

\subsection{Proportional growth in the number of consumers and firms}

The results are reversed if the number of firms increases proportionately with the growth in the number of consumers. We do it by fixing $n / I$ as $I$ increases, which implies a constant average individual output for each firm ${ }^{9}$ (Table III).

The decrease occurs both from integrated firms specializing upstream and downstream $^{10}$. This means, in first analysis, that the impact from increasing the number of firms (which lowers markups) overrides the impact of increasing the number of consumers. This can be interpreted as follows. By assuming a proportional growth, "the scale effect" for each firm is cancelled, so the "competition effect" dominates : the rise of the industry size induces a rise of competition, therefore a decrease in the markups (despite the demand growth) and finally a growing specialization (see 5.1).

Table III : Proportional growth in the number of consumers and firms (with $\beta$

$$
=0.02, \alpha=2 \text {, and } n / I=0.6 \text { ) }
$$

\begin{tabular}{|c|c|c|c|c|c|c|c|}
\hline $\mathrm{n}$ & 6 & 12 & 18 & 30 & 42 & 60 & 78 \\
$\mathrm{I}$ & 10 & 20 & 30 & 50 & 70 & 100 & 130 \\
\hline$\underline{\theta}$ & 0.09 & 0.18 & 0.24 & 0.31 & 0.36 & 0.4 & 0.43 \\
$\bar{\theta}$ & 0.98 & 0.85 & 0.78 & 0.70 & 0.66 & 0.6 & 0.56 \\
\hline Integrated firms (share) & $90 \%$ & $68 \%$ & $54 \%$ & $39 \%$ & $30 \%$ & $20 \%$ & $13 \%$ \\
Downstream F (share) & $8 \%$ & $17 \%$ & $24 \%$ & $31 \%$ & $36 \%$ & $40 \%$ & $43 \%$ \\
Upstream F (share) & $2 \%$ & $15 \%$ & $22 \%$ & $30 \%$ & $34 \%$ & $40 \%$ & $44 \%$ \\
\hline
\end{tabular}

\footnotetext{
${ }^{9}$ Because the average individual output for each firm can be written : $\bar{q}=\alpha(I / n)-\beta(I / n) \cdot p$

${ }^{10} \mathrm{We}$ checked that it is also accompanied by a drop in intermediate and final prices.
} 
Proposition 2 : A proportional growth in the number of consumers and firms leads to an increasing proportion of firms choosing to be vertically integrated.

However, we can't assert that the number of consumers and the number of producers are positively correlated, particularly in a model where average costs are continuously decreasing. So we can't clearly conclude on the validation of Stigler's thesis at this stage.

\subsection{Growth in the demand price}

Another way of considering demand growth is to assume an increase in the value granted to the final good by each consumer. A rise of $\alpha$ without modification of $\beta$ (equation 4) results in a fall of the consumption's price elasticity and in a rise of demand for a given price. Table 4 reveals that it results in a growing number of integrated firms.

Table IV : Growth in the value to consumers (with $\beta=0.02, I=25, n=15$ )

\begin{tabular}{|c|c|c|c|c|c|c|c|}
\hline$\alpha$ & 0.8 & 1 & 1.2 & 1.4 & 1.8 & 2.2 & 2.8 \\
\hline$\underline{\theta}$ & 0.37 & 0.34 & 0.31 & 0.28 & 0.23 & 0.19 & 0.13 \\
$\theta$ & 0.46 & 0.53 & 0.6 & 0.66 & 0.77 & 0.86 & 0.95 \\
\hline Integrated firms (share) & $8 \%$ & $19 \%$ & $29 \%$ & $38 \%$ & $54 \%$ & $67 \%$ & $82 \%$ \\
Downstream F (share) & $38 \%$ & $34 \%$ & $31 \%$ & $28 \%$ & $23 \%$ & $19 \%$ & $13 \%$ \\
Upstream F (share) & $54 \%$ & $47 \%$ & $40 \%$ & $34 \%$ & $23 \%$ & $14 \%$ & $5 \%$ \\
\hline
\end{tabular}

The explanation of this correlation is partly the same as in the case of a rise of the number of consumers $I$ (high fixed cost for integrated firms) but not only. A rise of $\alpha$ results here indeed in an increased final price, and also in an increased intermediate price, because oligopoly markups increase on each stage. Downstream firms benefit as well as the integrated firms from the growth in the value to consumers through the rise in the final price and quantities; but they also face the rise in the intermediate price. Thus, they will not benefit as much as the integrated firms from the rise of $\alpha$. Those that are close to $\underline{\theta}$ will be incited to integrate the upstream stage to catch the markup. This induces a decrease in the derived demand for the intermediate input which make it profitable for upstream firms near $\bar{\theta}$ to integrate forward. This tendency is reinforced by the fact that upstream firms benefit only partly, like the downstream firms, of the rise of $\alpha$. They can catch downstream markup while integrating forward. 
Proposition 3 : A growth in the value the consumers grant to the final product results in an increasing proportion of firms choosing to be vertically integrated.

A real problem of double marginalization appears here : specialized firms on each stage choose prices and quantities without considering the impact on the profits of the other stage firms. By eliminating the double marginalization, vertical integration greatly modifies the structure of the intermediate market and thus the margins of the specialized firms.

\section{Conclusion}

This paper has examined, in a model of successive Cournot oligopolies, how a modification of the market size could impact on the degree of vertical integration in an industry. This model differs from most of vertical equilibrium models because it introduces explicitly the benefits of vertical disintegration which derive from differences between the firms in their efficiency in producing intermediate and final goods. Vertical integration is motivated by the double mark-up effect. Given a linear final demand, we can then define a vertical equilibrium where firms choose to operate on one or both of the two stages according to their skills. This equilibrium is affected by industry growth. If industry growth is defined as an increase in the value granted to the final good, then the net impact of growth is a higher proportion of vertically integrated firms, because of the subsequent higher mark-ups on each stage. The net impact is the same if industry growth is defined as an increase in the number of consumers, because integrated firms with higher fixed costs benefit more from the rising production scale. However, the result is reversed if we suppose, in order to cancel the scale effect, a proportional increase in the number of firms and consumers. A lower proportion of firms choose to integrate both stages, because of the diminishing impact of double mark-up effect when the number of firms increases. So, only one case of demand growth conforms to Stigler's hypothesis of positive correlation between industrial specialization and industry growth in our two stages model with Cournot competition.

Finally this model can also contribute to research on the effect of vertical integration on the final price (and on the consumer's surplus) in the context of successive oligopolies. In our model, an increase in the proportion of integrated firms induces ceteris paribus a decrease in the final price.

\section{COLOPHON}

I thank the participants of the 19th Days on Applied Microeconomics in Rennes in 2002, the members of the CREM, as well as two anonymous referees for their helpful critiques and comments. 


\section{REFERENCES}

Elberfeld, W., (2002), «Market and vertical integration: Stigler's hypothesis reconsidered », Journal of Industrial Economics, L, 1, 23-42.

Gaudet, G. and Van Long, N., (1995), Vertical integration, foreclosure and profits in the presence of double marginalization, Journal of Economics and Management Strategy, 5, 409-432.

Gaudet, G., Van long, N. and Soubeyran, A., (1996), "Upstream-downstream specialization by integrated firms in a partially integrated industry", Cahiers de Recherche 9604, Université Laval, Departement d'Economique.

Levy, D.T. (1984), “Testing stigler's interpretation of 'The division of labor is limited by the extent of the market", Journal of Industrial Economics, n³2, 377-389.

Perry, M.K., (1984), Vertical equilibrium in a competitive input market, International Journal of Industrial Organization, vol.2, 159-170.

Perry, M.K. and R.H. Groff, (1988) "Vertical integration and industry growth ", Bell Laboratory Discussion Paper.

Pigou, A.C. (1932) The Economics of Welfare, Macmillan, London.

Salinger, M.A. (1988) "Vertical mergers and market foreclosure", Quarterly Journal of Economics, vol.103, 345-356.

Stigler, G.J. (1951) "The division of labor is limited by the extent of the market", Journal of Political Economy, vol.59(3), 185-193.

Stuckey, V.A. (1983), Vertical Integration and Joint Ventures in the Aluminium Industry, Cambridge, Havard University Press.

Tucker, I.B and R.P Wilder, (1984), « Trends in vertical integration : reply », Journal of Industrial Economics, vol.32, n³, 391-392.

White, L.J. (1978), "The division of labor is limited by the standardization in the market : a note on Stigler's vertical integration theme", Industrial Organization Review, 5, 142 143.

Wright, M. and S. Thompson, (1986), "Vertical disintegration and the life cycle of firms and industries", Managerial and Decision Economics, vol.7, pp.141-144.

Young, A., (1928), "Increasing returns and economic progress", Economic Journal, 38, 527-542. 